\title{
Mitochondrial links between brain aging and Alzheimer's disease
}

\author{
Heather M. Wilkins ${ }^{1,2,3}$ and Russell H. Swerdlow ${ }^{1,2,3,4^{*}}$ (])
}

\begin{abstract}
Advancing age is a major risk factor for Alzheimer's disease (AD). This raises the question of whether AD biology mechanistically diverges from aging biology or alternatively represents exaggerated aging. Correlative and modeling studies can inform this question, but without a firm grasp of what drives aging and AD it is difficult to definitively resolve this quandary. This review speculates over the relevance of a particular hallmark of aging, mitochondrial function, to $A D$, and further provides background information that is pertinent to and provides perspective on this speculation.
\end{abstract}

Keywords: Aging, Alzheimer's disease, Mitochondria, Mitochondrial DNA

\section{Background}

Higher organisms invariably age. For those moving forward from life's beginning, aging may manifest as physical growth and the acquisition of new abilities. For organisms approaching the end of life aging more typically manifests as increased frailty, disability, and risk of death. Investigators who study the biology of aging, especially its later life trajectory, identify "hallmark" biological features that associate with aging, and may contribute to the aging process [1].

Aging clearly alters people's lives independent of disease, although we do not classically view aging-driven morbidity with the same urgency as disease-driven morbidity. In some cases, these morbidities overlap qualitatively and arguably differ mostly on a quantitative level. For example, with advancing age the ability to retain new information declines in humans, but until relatively recently the medical field has assumed that limited cognitive decline in elderly individuals does not imply disease and referred to this phenomenon as age-associated cognitive decline (AACD) or age-associated memory

${ }^{*}$ Correspondence: rswerdlow@kumc.edu

1 University of Kansas Alzheimer's Disease Research Center, Kansas City, KS, USA

Full list of author information is available at the end of the article impairment (AAMI) [2]. Currently, however, medical practitioners recognize that although not all cognitive changes that occur with aging represent $\mathrm{AD}$ or will evolve to $\mathrm{AD}$, these are not necessarily benign syndromes $[3,4]$. When manifesting in the absence of objective cognitive deficits they are now sometimes preferably characterized as subjective cognitive decline (SCD) [5], and as mild cognitive impairment (MCI) when objective cognitive deficits are present in the absence of frank dementia [6].

The realization that subtle cognitive change often progresses over time to become functionally consequential has helped change the initial perspective. Moreover, the brains of individuals with SCD and MCI frequently contain plaques and tangles, histologic features used to define Alzheimer's disease (AD). This complicates the question of where to draw the line between AACD, AAMI, SCD, MCI and AD. One way to simplify this decision, as proposed by Jack et al., is to think of it as $\mathrm{AD}$, or at least as an "AD continuum" when plaques are present [7] and to think of it as aging when they are not.

This approach could make sense if amyloid plaques are in fact the proximal cause of $\mathrm{AD}$, and additionally if the biology of amyloidosis and the biology of aging are completely independent. Currently we do not know the answer to either of these points, but there are reasons original author(s) and the source, provide a link to the Creative Commons licence, and indicate if changes were made. The images or other third party material in this article are included in the article's Creative Commons licence, unless indicated otherwise in a credit line to the material. If material is not included in the article's Creative Commons licence and your intended use is not permitted by statutory regulation or exceeds the permitted use, you will need to obtain permission directly from the copyright holder. To view a copy of this licence, visit http://creativecommons.org/licenses/by/4.0/. The Creative Commons Public Domain Dedication waiver (http://creativeco mmons.org/publicdomain/zero/1.0/) applies to the data made available in this article, unless otherwise stated in a credit line to the data. 
to suspect neither is the case. In fact, to understand AD what we truly need is a reliable mechanistic definition of AD. Linking aging mechanisms with AD mechanisms can help inform the development of an AD mechanistic definition. To this end, mitochondria, which are implicated in both aging and $\mathrm{AD}[8]$, warrant consideration.

\section{Mitochondria: leading the fight against entropy}

Organisms need energy to maintain form and function. Without energy, entropy overwhelms life. The need to acquire energy and consume it is a critical factor that underlies billions of years of evolution. The procurement of energy from the environment, initially from fermentable substrates and then the sun, drove the creation of all life's building blocks. In some cases, this success in turn altered the environment; the earth's current oxygen atmosphere is essentially a direct consequence of photosynthesis. A changing environment in turn prompted additional evolution, including the emergence of mitochondria specialized to capture energy stored in covalent bonds by using it to generate high-energy electrons, harvesting that electron energy in the respiratory chain, and delivering the spent electrons to oxygen.

Eukaryotic cells arose partly through evolutionary advances in energy biology that prompted the emergence of multicellularity. Multicellularity itself developed to efficiently provide energy substrates to individual cells, which could henceforth work together to their advantage. The brain itself is perhaps the ultimate culmination of this process.

Circulation systems developed to deliver energy substrates to cells present in emerging tissues and organs, and to remove byproducts of energy metabolism. The circulatory system brings oxygen and carbon fuels to all parts of the body and carries off carbon dioxide and in some cases newly generated carbon molecules. Without the need to support energy acquisition and production, there is perhaps no need for a circulatory system. For many cell types, including neurons, mitochondria are responsible for laundering energy acquired from external sources to forms they can utilize.

Other reviews have detailed the intricacies of mitochondrial function. Briefly, organic molecules including fatty acids, amino acids, carbon-based molecules derived from fat, and carbon-based molecules derived from glucose enter the organelle. Enzymes within the mitochondria break down those molecules and direct the newly generated carbon pieces elsewhere. Energy released during this process drives redox reactions that feature the reduction of the oxidized form of nicotinamide adenine dinucleotide (NAD+) to NADH and flavin adenine dinucleotide (FAD) to FADH2. NADH and FADH2 can donate their thusly acquired, relatively high-energy electrons to a respiratory chain that gradually milks the energy from those electrons to pump protons from one side of a membrane to another. This creates electrochemical and $\mathrm{pH}$ gradients across the membrane. Energy released during a physiologic discharge of these gradients is captured in the form of the phosphate bond that defines the conversion of ADP to ATP. The spent electron is ideally disposed of by the enzyme cytochrome oxidase (COX; complex IV), which passes 4 electrons at a time to molecular oxygen $\left(\mathrm{O}_{2}\right)$ and protons to generate water.

Other reviews have detailed different aspects of mitochondrial biology. These include mitochondrial biogenesis, the process through which cells renew their mitochondria or expand the amount of mitochondria they contain [9]; mitophagy, the process through which cells remove mitochondria or parts of mitochondria [10]; mitochondrial fission and fusion, which allows mitochondria to either discard spent parts or to function in a complementary fashion [11]; and mitochondrial movement, which distributes mitochondria to different parts of cells [12].

In addition to a central role in cell energy production, mitochondria are also a critical source for macromolecule synthesis. For example, carbon entering the Krebs cycle as acetyl CoA can exit the mitochondria at the citrate intermediate step, and in the cytosol that citrate is subject to an ATP-dependent lyase reaction that releases an acetyl CoA, which is used to synthesize lipid molecules. Overall, in this case the mitochondria determine the ultimate destination of glucose-derived carbon, which ends up as lipid carbon.

Mitochondrial physiology plays a role in other cell physiologies, including oxidative stress, calcium homeostasis, iron homeostasis, phospholipid synthesis, cell death, protein trafficking, and proteostasis. They alter multiple signaling cascades. Mitochondria communicate to the nucleus through a process called retrograde signaling [13], which provides information on the state of the mitochondria specifically and the state of the cell in general to the nucleus.

The communication between mitochondria and the nucleus is particularly important as part of the mitochondrial proteome is encoded by DNA contained within the mitochondria itself, the mitochondrial DNA (mtDNA), while the rest of the mitochondrial proteome is encoded by nuclear genes that are translated outside of the mitochondria and the newly synthesized proteins are subsequently transported into the mitochondria. Mitochondrial proteomes differ between different cell types $[14,15]$, consistent with the observation that mitochondria in different cell types may emphasize different cell contributions. For instance, neuron mitochondria lack the enzymes required to perform fatty acid $\beta$-oxidation, 
while astrocyte mitochondria contain those enzymes [16]. This keeps neurons from consuming fatty acids, which is potentially advantageous for maintenance of extensive membrane, while possibly allowing astrocytes to generate ketone bodies that can subsequently transfer to neurons and support neuron oxidative phosphorylation [17]. A similar relationship is apparent when it comes to glucose utilization. Astrocytes can exploit aerobic glycolysis to produce lactate, which can subsequently transfer to neurons where it supports neuron oxidative phosphorylation [18].

\section{Mitochondrial aging, mitochondria in aging}

There is consensus that mitochondria change with advancing age [19]. Studies have demonstrated agerelated declines in mitochondrial mass, respiration capacity, and respiration efficiency. Such changes appear to span multiple tissues. Many investigators, but not all, have reported a relative increase in the burden of heteroplasmic mtDNA mutations [20, 21], which manifest as both point mutations and deletions. Surprisingly, the relationship of mtDNA copy number with aging is unclear as the literature reports findings of increased, unchanged, or decreased mtDNA copy number with aging [22]. Although the discrepancy can be partly explained by the use of different tissues for measurement, which has yielded different results, there are indeed inconsistencies among different studies on the mtDNA copy number change in a particular tissue. Model utilization and methodologic factors presumably contribute to this inconsistency [23].

Other biological parameters that are related to mitochondria also change with age. Oxidative stress is a welldescribed parameter that increases with advancing age [24]. This manifests as increased DNA oxidation, and in general, with advancing age mtDNA oxidation accumulates more rapidly than nuclear DNA (nDNA) oxidation [25].

In many species, especially in humans, some potential confounders should be considered. For example, older individuals are likely more sedentary than younger individuals. This could lead to muscle deconditioning, which may in turn affect muscle mitochondria. Also, many tissues contain more than one type of cell and this could influence the outcomes. Consider the case of blood, which contains red blood cells, white blood cells, and platelets. The mature red blood cells predictably lack nDNA and mtDNA, and platelets contain mtDNA but not nDNA. The white blood cells contain both. Since the mtDNA copy number determination frequently relies on the measured mtDNA-to-nDNA ratio in a sample, the extent of enrichment of the white blood cells relative to the platelets in the assay can have a critical impact. This scenario also applies to the brain. Levels of neuron and astrocyte mtDNA may differ, as may age-related neuron and astrocyte changes. Separating neurons and astrocytes requires a concerted effort, and even when applied, such procedures can produce different degrees of celltype enrichment.

The nDNA also contains mtDNA pseudogenes, referred to as nuclear-mtDNA (NUMT) sequences, which can influence the mtDNA-to-nDNA ratio determinations. The procedure used to harvest DNA from cells is also consequential, as some approaches may preferentially exclude mtDNA from the assayed sample and thereby skew the true mtDNA-to-nDNA ratio [23].

Whether the age-associated changes to mitochondria are a consequence of aging or drive aging is unclear. Classic mechanistic-oriented aging hypotheses, such as the free radical theory of aging, have been formulated from the perspective that mitochondria drive aging $[26,27]$. The free radical hypothesis speculates that free radicals generated by the mitochondrial respiratory chain oxidize cell molecules to the point of perturbing their function over time. Some investigators went a step further to propose a particular molecule that might accumulate longitudinal damage and manifest a progressive functional decline, thereby serving as an aging "clock" [28]. The observation that levels of mtDNA somatic mutation rise with increasing age supports the speculation that mtDNA might constitute that clock [20,29].

To better assess the cause versus consequence question, investigators turned to or developed animal models. As might be expected, such studies established valuable precedents while raising further questions. One influential model is the mtDNA mutator mouse, which features a proofreading mutation of the mtDNA polymerase gamma that mediates mtDNA replication [30, 31]. These mice acquire mtDNA mutations at an accelerated pace and manifest phenotypes that are consistent with accelerated aging. This would seem to resolve the issue of whether mtDNA-derived changes in mitochondrial function can drive aging, but some cautions should be taken against extrapolating conclusions from the mutator mice to human aging [32-34]. The homozygous mutants, which demonstrate accelerated aging phenotypes, accumulate levels of mutation that far exceed levels found in aging humans. The heterozygous mutants also accumulate higher levels of mtDNA mutation than those found in aging humans, but do not show accelerated aging phenotypes. In addition, neither the homozygous nor the heterozygous mutants show evidence of oxidative stress, which argues against the role of free radicals as a requisite intermediary.

Different models have also generated, at least at a superficial level, conflicting results. While the mtDNA 
mutator mouse data suggest that free radicals do not impact aging $[35,36]$, in some cases the increased expression of enzymes that counter mitochondrial oxidative stress prolongs longevity in mice [37]. Further complicating the picture, some models designed to or some interventions intended to enhance mitochondrial function show extended lifespan, while some models designed or interventions intended to interfere or reduce mitochondrial function also paradoxically show extended lifespan [38].

A deeper understanding of the myriad changes that arise in these simplified models, and the reasons underlying these changes, will hopefully eventually resolve at least some of these apparent conflicts. Reactive oxygen species (ROS), for instance, may alternatively harm or protect cells. The classic thinking that ROS serves mostly to damage lipids, DNA, and proteins is being replaced by a more recent appreciation of its physiologic roles, which include cell signaling and the activation of hormetic responses [39]. ROS may also provide cells with a mechanism that allows them to better regulate their oxygen levels. This could prove particularly important in the setting of respiratory chain dysfunction as the respiratory chain is responsible for the majority of cell oxygen consumption. It is worth considering that a primary reduction in mitochondrial respiration could induce a state of intracellular hyperoxia, with protean secondary effects such as a reduction in hypoxia induction factor 1 alpha (HIF1 $\alpha$ ) signaling. In this case the generation of ROS could conceivably help restore the cell oxygen level to a more physiologic state and consequently normalize HIF $1 \alpha$ activity [40]. Figure 1 illustrates this scenario. At least one study performed in C. elegans is consistent with this possibility [41]. A comprehensive yet precise understanding of the biological consequences of different mitochondrial manipulations may lead to a better understanding of the mitochondrial-aging nexus.

\section{Mitochondria in AD}

When analyzing groups of mitochondria from persons with $\mathrm{AD}$ and from persons who are cognitively normal, on multiple parameters the mitochondria between the two groups do not function equivalently or otherwise appear distinct [42-45]. Some differences may reflect bona fide lesions or pathology, while others likely reflect adaptations or compensations. The altered mitochondriaassociated endpoints can be internal or external to the mitochondria themselves. In some instances, differences

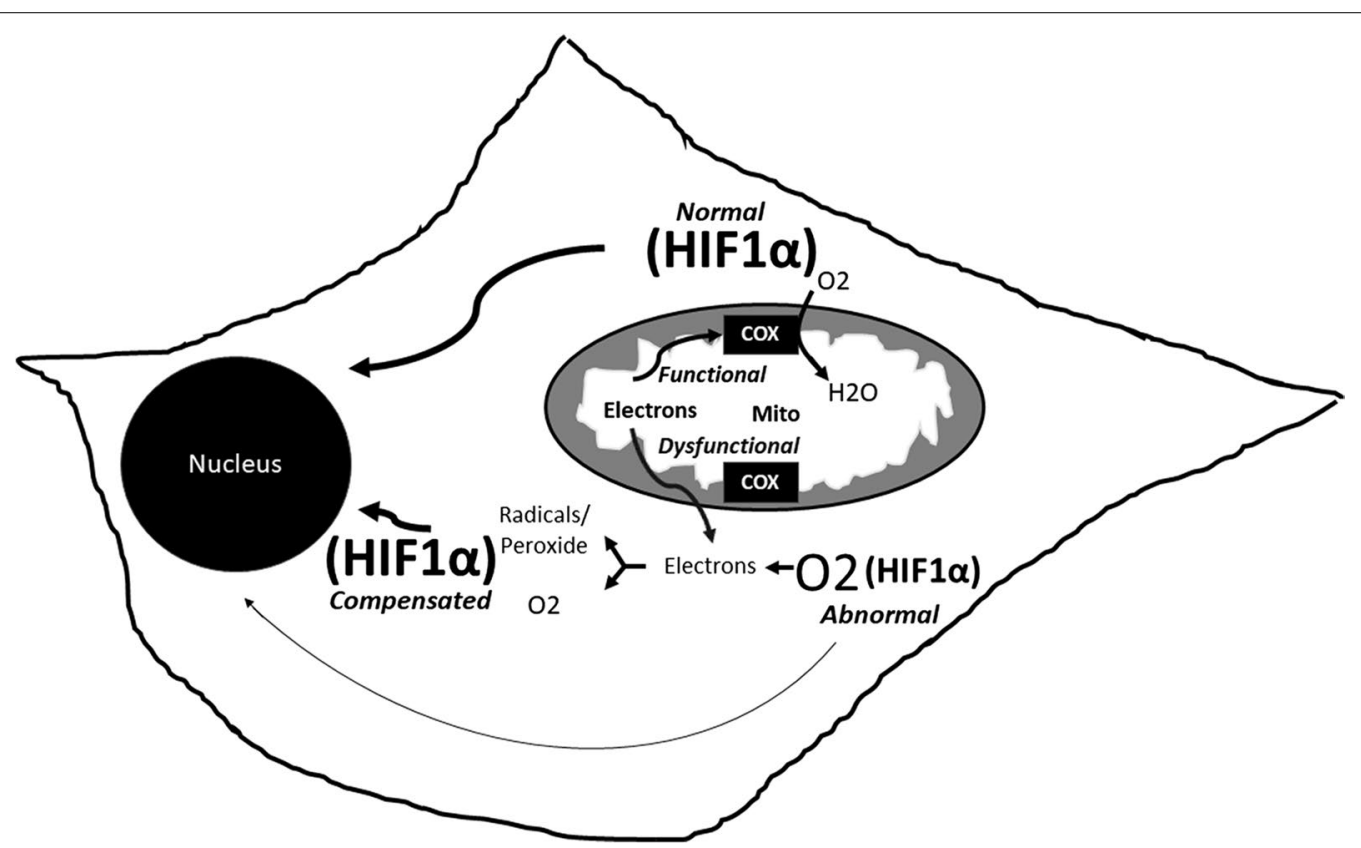

Fig. 1 Oxidative stress helps modulate HIF1a levels. In the cell depicted, when the mitochondrial respiratory chain functions appropriately, $\mathrm{O}_{2}$ is consumed at COX, which keeps $\mathrm{O}_{2}$ from accumulating and creates a HIF1a setpoint. With mitochondrial respiratory chain failure, intracellular hyperoxia can develop, with a consequent reduction in HIF1a. The respiratory chain dysfunction can cause electron egress from the mitochondria and subsequent production of free radicals and hydrogen peroxide, which can boost HIF1a levels by relieving hyperoxia or by accomplishing HIF1a stabilization. The thickness of the line leading from HIF1a to the nucleus is intended to confer greater versus lesser amounts of HIF1a signaling within the cell. Mito, mitochondria 
represent an exaggeration of age-associated changes. In others, the differences are unique.

Of critical importance, mitochondrial alterations are not brain-limited. The differences are also seen in platelets, fibroblasts, and muscle [42, 46-48]. This implies that the alterations are not exclusively a consequence of neurodegeneration, and probably not exclusively caused by the classic $\mathrm{AD} A \beta$-plaque and tau-tangle biomarkers. They are seen in individuals with the MCI syndrome [49], which often manifests as a precursor to AD with dementia.

The age-related reductions in respiratory chain capacity and efficiency are aggravated in AD. The COX activity or related function is lower in AD brain tissues, platelets, and fibroblasts than in age-matched groups $[42,50]$. Heteroplasmic mutations that accumulate with advancing age accumulate to a greater degree in $\mathrm{AD}[25,51]$. The mitochondrial fission-fusion balance shifts towards fission $[52,53]$, and AD brain and cell models show a relative reduction in mitochondrial movement $[54,55]$. Overall, AD brain mitochondria are smaller in size, yet manifest increased numbers of swollen organelles with disrupted cristae $[43,56,57]$. Reductions in peroxisome proliferator-activated receptor gamma coactivator 1 alpha at both protein and mRNA levels suggest reduced mitochondrial biogenesis $[58,59]$. Decreased mitophagy has also been reported [60], although one study has noted an increase in autophagosomes containing mitochondrial detritus [61]. Oxidative stress has been consistently reported to increase [62], and it is tempting to link this phenomenon, as well as reduced COX activity, to an apparent reduction in HIF1 $\alpha$ signaling [63].

In $\mathrm{AD}$, the HIF1 $\alpha$ system seems especially vulnerable to mitochondrial dysfunction. HIF $1 \alpha$ is constitutively expressed. However, in the presence of sufficient cell oxygen, a set of prolyl hydroxylase domain-containing enzymes will utilize oxygen, in conjunction with cytosolic $\alpha$-ketoglutarate and ferrous iron, to hydroxylate HIF1 $\alpha$ proline [64]. This proline hydroxylation targets HIF $1 \alpha$ for ubiquitination and removal via the proteosome. In this situation, HIF1 $\alpha$ is not available to move to the nucleus and cannot drive the expression of its dependent genes. When cell oxygen levels are low, hydroxylation of HIF $1 \alpha$ proline cannot occur, and HIF $1 \alpha$ is not degraded and thus can promote gene expression.

Through sensing cell oxygen levels and coordinating a response to those levels, HIF $1 \alpha$ modulates energy metabolism and its pertinent fluxes. HIF1 $\alpha$ signaling promotes glycolysis and restrains mitochondrial respiration [64]. Its action, though, seems designed to help cells respond to environmental oxygen levels. In general, the HIF $1 \alpha$ system encourages cells to generate ATP through respiration when oxygen is adequate, and to generate ATP through fermentation when it is not [65]. In the setting of a primary mitochondrial dysfunction, this could present a conundrum. If oxygen levels rise because it is not consumed by the respiratory chain, HIF $1 \alpha$ would be downregulated, and a subsequent reduction in glycolysis could exacerbate bioenergetic stress.

Studies of AD brains have more consistently reported reduced mtDNA than studies of aging brains [66-68], despite a notable increase in autophagosome mtDNA, which contains large amounts of mtDNA deletion [61]. The mtDNA decrease in AD brain may not simply reflect an artifact of reduced neuron number, as a previous study that quantified mtDNA deletions in single neurons reported elevated levels of mtDNA deletions and established that mtDNA in AD neurons is indeed altered [69]. Cerebrospinal fluid (CSF) mtDNA is also lower in $\mathrm{AD}$ than in control CSF [70]. One study has reported evidence of a reduction in lymphocyte mtDNA [71].

The anatomically widespread localization of altered mitochondrial function in $\mathrm{AD}$ raises the question of its origin. Cytoplasmic hybrid (cybrid) studies argue that factors intrinsic to the mitochondria themselves, especially mtDNA, contribute to this [8]. In these studies, mitochondria from, usually platelets, of $\mathrm{AD}$ or agematched control subjects are transferred to cell lines completely depleted of endogenous mtDNA, or $\rho 0$ cells [72]. The mtDNA contained within the transferred mitochondria repopulates the $\rho 0$ cells and restores the lost mitochondrial functions. The groups of cybrid cell lines generated through the transfer of $\mathrm{AD}$ subject platelet mitochondria show persistent differences in mitochondrial function when compared to the cybrid cell lines receiving control subject mitochondria [73]. As these cells have the same nuclear content and are maintained under identical conditions, the difference in mitochondrial function most likely arises from and indicates differences in mtDNA.

Differences between $\mathrm{AD}$ and control cybrid lines are subtle but diverse. As is the case in multiple primary tissues, COX activity is lower in the $\mathrm{AD}$ subject-generated cybrids [8]. The AD subject-generated cybrids display elevated levels of oxidative stress, a reduced mitochondrial membrane potential, a reduced ability to buffer changes in cytosolic calcium, reduced mitochondrial movement, and a smaller overall size despite an increase in swollen mitochondria with disrupted cristae. Several markers of mitochondrial biogenesis appear lower.

The precise nature of the presumed responsible $\mathrm{AD}$ subject mtDNA signature thus far remains unclear. There does not appear to be a single mtDNA variant responsible for these differences. To date, there is no evidence for a heteroplasmic mutation, whether somatically acquired or inherited. Recent studies, however, do reveal that 
cybrid cell lines containing mtDNA from different haplogroups function differently [74]. This suggests that certain mtDNA variants occurring in combination may play a role. This view has been supported by genetic association studies [75]. The mtDNA control region also demonstrates an impressive degree of diversity between individuals, and some of this control region diversity is haplogroup-specific. Studies of AD brain mtDNA do suggest that some control region variants differ between $\mathrm{AD}$ and controls [76]. As the mtDNA control region helps determine mtDNA replication and transcription, it can affect a variety of mitochondrial functions. One cybrid study found a small but consistent decrease in mtDNA copy number in AD subject-generated cybrid lines relative to control subject-generated cybrid lines [77], potentially consistent with the possibility that the mtDNA copy number represents a source of at least some altered mitochondrial functions in $\mathrm{AD}$, and that the lower levels of mtDNA are potentially mediated by inherited combinations of control region variants.

Some aspects of $\mathrm{AD}$ mitochondrial function, however, likely arise extrinsic to the mitochondria themselves. Several studies have reported that amyloid precursor protein (APP) and A $\beta$ localize to mitochondria, and $A \beta$ appears to act as a mitochondrial toxin [78-85]. The tau protein also appears to localize to mitochondria and contribute to mitochondrial dysfunction through multiple mechanisms [86-92]. Similarly, a cleavage product from the apolipoprotein $\mathrm{E}$ protein displays a mitochondrial localization signal, targets mitochondria, and inhibits COX activity $[93,94]$. Due to the differences in protein folding, apolipoprotein $\mathrm{E}$ encoded by the APOE4 isoform generates larger amounts of the mitochondrial-targeting cleavage peptide. Recent studies have found that the COX activity in platelet mitochondria of $\mathrm{AD}$ subjects is lower in APOE4 carriers than in APOE4 non-carriers [95, 96]. Overall, the differences in mitochondrial function may arise at least to some extent from the differences in mtDNA and nuclear genes, a view that can readily explain the systemic AD biochemical and molecular phenotypes. Because mitochondria also influence other biological modules implicated in $\mathrm{AD}$, such as endosomal function, lipid biology, and innate immunity and inflammation [97], there are valid reasons to propose that mitochondria play a primary rather than a secondary role in AD. This idea is captured by the AD mitochondrial cascade hypothesis [50, 98-101].

\section{Mitochondria: the missing mechanistic link between aging and AD?}

If mitochondria represent a common underlying hallmark of both aging and AD, then it is possible that a situation could exist in which during aging, the mitochondrial drivers remain minor enough to permit an adequate functional compensation, whereas in $\mathrm{AD}$ adequate compensation is not possible. Under this scenario, "compensated" brain aging can give way to "uncompensated" brain aging. The basis for this is simply the mitochondrial decline progressing past a critical point. A progressive age-related decline in respiratory chain function, for example, could potentially drive such a phenomenon.

In a slightly different but distinct modification of this scenario, a unique mitochondrial change could arise that then triggers the transition from aging to disease. The difference from the scenario described above is that progressive age-related mitochondrial changes come to eventually alter mitochondria in a way not typically observed during compensated aging. By way of example, if it is correct that the mtDNA copy number truly does not fall with advancing age but does during $\mathrm{AD}$, then the point at which mtDNA copy number falls would represent the start of the disease. Ultimately, both these possibilities could play out.

Of course, the question of how the classic AD pathologies relate to any of this is critical to this discussion. Alois Alzheimer described the classic features over a century ago [102, 103], and a series of more recent hypothesisdriven and unbiased "omic" studies have identified subsequent additional ones [104, 105]. Plaques and tangles are seen in older persons independent of clinical changes, and among cognitively intact individuals the likelihood of their presence increases with increasing age [106]. If clinical symptoms define the border between the absence versus presence of $\mathrm{AD}$, then plaques and tangles themselves are age-associated changes and perhaps even driven by aging or whatever it is that drives aging. This would infer that the plaques and tangles, toxic or not, are at least a consequence of an upstream biology that allows for or drives their appearance. Complicating this consideration are recent attempts to redefine $\mathrm{AD}$ as simply the presence of plaques and tangles, regardless of clinical status [7], but mechanistic considerations do not inform this convention.

Well-documented links exist between mitochondria and $A \beta$-related biology. The APP from which A $\beta$ derives contains a mitochondrial targeting sequence [78-80]. APP is seen in mitochondria, where it appears to lodge within the translocase of the outer mitochondrial membrane $40 \mathrm{kD}$ complex. APP has been reported to interfere with $\mathrm{COX}$ activity. $\mathrm{A} \beta$ itself is found within mitochondria, where it may disrupt the function of several proteins [81, 83, 84]. Perturbing mitochondrial or bioenergetic function, alternatively, alters APP processing, and through this, presumably $A \beta$ generation [107109]. With respect to understanding the relationships between mitochondria, APP and A $\beta$, one might first need 
a better understanding in general of APP's roles within a cell, and specifically at the mitochondria. It would be helpful to know what factors regulate mitochondrial APP accumulation. The field has already recognized some factors that can link the two biologies to each other. Iron is one example, as mitochondria play a critical role in iron homeostasis, and iron levels also regulate APP expression [110].

Links also exist between mitochondria and tau biology. Tau localization to mitochondria has been reported and it interferes with mitochondrial function through multiple mechanisms [86-92]. Conversely, various mitochondrial toxins increase tau phosphorylation and oligomerization [111-117]. Both chronic and acute mtDNA depletion result in increased cell total tau, increased oligomer tau, and in the case of chronic mtDNA depletion, a relative shift from monomer to oligomer tau [77]. Cybrid cell lines derived from AD subjects on average contain more oligomer tau than cybrid cell lines derived from cognitively normal subjects [77].

Mitochondria could also potentially provide insight into how apolipoprotein E influences AD risk. Although several hypotheses exist [118], this almost 30-year conundrum remains incompletely resolved. As mentioned in the previous section, one hypothesis is built on the observation that an apolipoprotein E cleavage product, excessively generated from the APOE4 isoform, targets mitochondria and acts as a mitochondrial toxin [93, 94]. As $A P O E$ gene expression is typically quite limited in neurons and occurs mostly in astrocytes and microglia $[119,120]$, presumably in this scenario neuronal $A P O E$ expression must begin to occur. One very recent study reported that this is indeed the case [121]. However, that study fell short of identifying what event might occur in neurons to turn on their APOE production. It would be interesting to test whether altered mitochondrial function can turn on neuron APOE expression. If this in fact happens, one possible mechanism that ties aging to $\mathrm{AD}$ could occur as follows: age-related changes in mitochondrial function occur, these changes reach a point that they turn on neuron $A P O E$ expression, the apolipoprotein $E$ or a cleavage product localizes to the mitochondria to further interfere with mitochondrial function, and the degree of mitochondrial compromise within the cell worsens to surpass the ability of the cell to compensate (Fig. 2). Because APOE4 generates higher levels of the mitochondrial toxin, under this scenario APOE4 would prove relatively detrimental when compared to the other APOE isoforms.

This of course has treatment implications. APOE genetics arguably offer therapeutic clues, but how to best leverage apolipoprotein $\mathrm{E}$ biology for treatment purposes is a complex issue. On a general level, a loss of function could justify increasing the levels, while a toxic gain of function could justify decreasing the levels. On a more isoform-specific level, some might argue for increasing the levels of the "protective" APOE2 isoform, while others might argue that the best approach is to decrease the levels of the "toxic" APOE4 isoform. Under the scenario described above, a logically directed approach would be to prevent the expression of APOE, regardless of the isoform but especially in the presence of APOE4, within neurons.

\section{Additional considerations}

This review narrowly focuses on the relationships between mitochondria and aging, and between mitochondria and $\mathrm{AD}$, while trying to make a case for how mitochondria could link aging to AD. If this perspective is correct, it may be worth considering whether mitochondria in fact initiate AD [50, 98-100]. This would of course conflict with the current popular hypothesis, the amyloid cascade hypothesis [122], that has strongly influenced AD research for three decades despite robust dissent. Criticisms are leveled from multiple angles, such as the repeated observation that plaque burden sub-optimally correlates with cognitive deficits [123-125], and the more recent appreciation that reducing $A \beta$, by preventing production or promoting removal, will at best minimally benefit patients [126]. Partly for these reasons, interest in other etiologic hypotheses has emerged. This includes an emerging interest in tau [127], whose fibrillar presence in the form of tangles quantitatively correlates well with cognitive decline [128].

It is also important to recognize that $\mathrm{AD}$ is divided into subtypes whose etiologies may or may not overlap. A prominent distinction exists between late-onset $\mathrm{AD}$ (LOAD), which does not show a classic Mendelian inheritance pattern, and early-onset familial $\mathrm{AD}$, which does [106]. Advancing age would most obviously prove pertinent to LOAD. However, if the role of deterministic mutations is to reduce the amount of age-related mitochondrial decline needed to initiate clinical disease, for example by retarding mitochondrial resilience or the brain's ability to tolerate age-related mitochondrial dysfunction, it is conceivable that age-related mitochondrial changes could contribute to early-onset familial AD.

\section{Conclusions}

To advance our understanding of the aging-AD nexus, we must first overcome several challenges. On the one hand, aging is a complex process that implicates multiple contributing factors, any of which alone or in combination could prove pertinent to $\mathrm{AD}$. On the other hand, despite remarkable advances in our ability to detect $\mathrm{AD}$ 


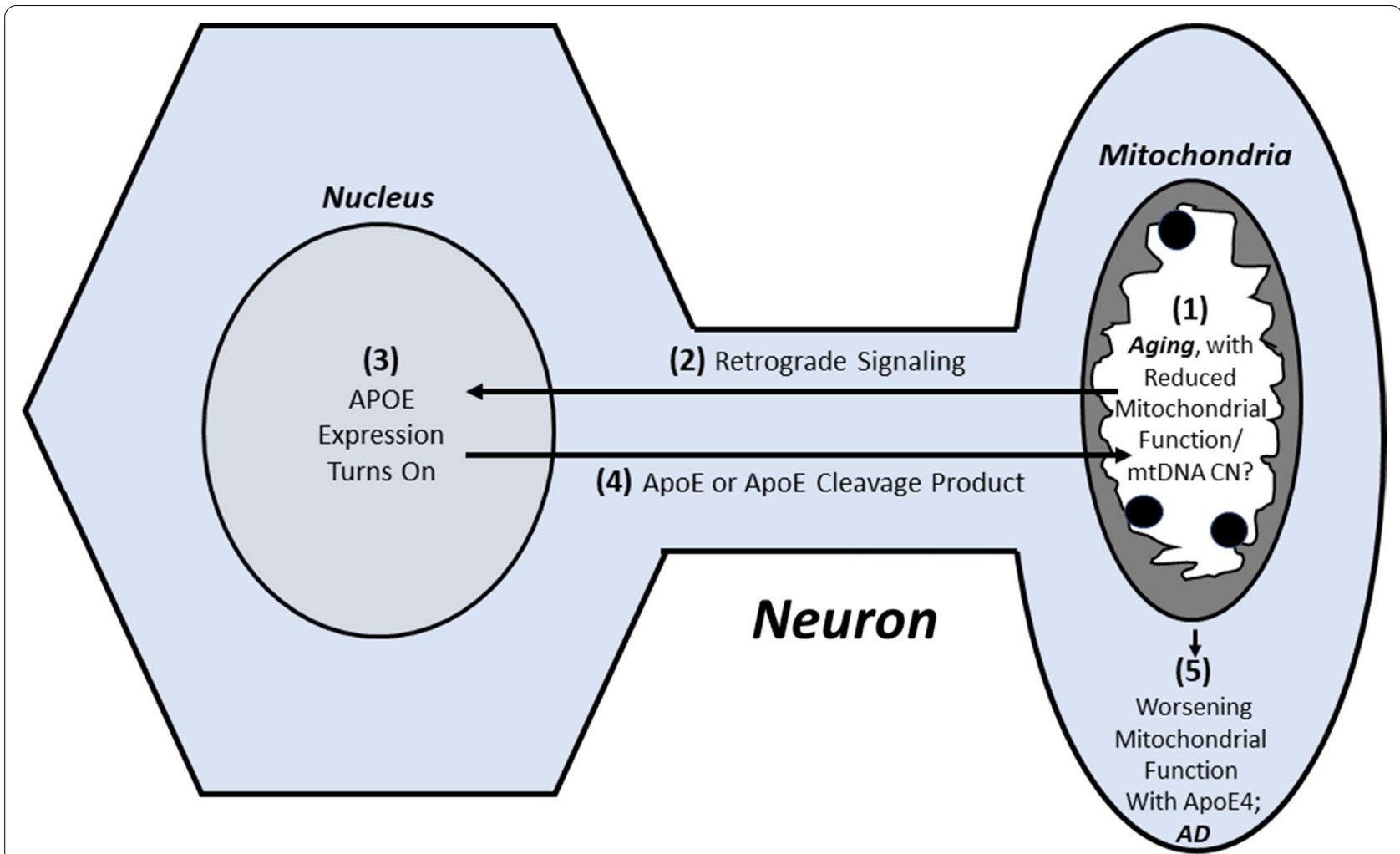

Fig. 2 Could age-related changes to mitochondria alter ApoE biology? Neurons do not typically express the APOE gene to produce ApoE protein, but may begin to express it in the setting of an age-related decline of mitochondrial function or mtDNA copy number. The ApoE protein that is produced, or a cleavage product of ApoE, may then interact with mitochondria. If the APOE isoform is APOE4, this may confer a toxic effect that further perturbs mitochondrial function and pushes the brain from a state of compensated to uncompensated brain aging, a state equivalent to AD. While this illustration presents a dramatically simplified scenario, it conceptualizes a series of events through which biological changes typically associated with aging could transition into biological changes typically associated with $A D$

pathologies in living individuals, our understanding of what drives these pathologies remains incomplete.

The new biomarker-based "biological" AD definition [7], to some extent, also presents a challenge. Intentionally or not, it creates an arbitrary divide that conceptually separates aging from $\mathrm{AD}$ as aging with plaques and tangles is simply designated AD. While this approach may facilitate the standardization of participant groups entering clinical trials, equating biomarkers with disease does not necessarily explain why those biomarkers arose or how they got there. Arguably what the field really needs to develop is a "mechanistic" definition of $\mathrm{AD}$. To this point, the remarkable positive correlation of advancing age with $\mathrm{AD}$ incidence and prevalence can provide clues on where to look [106]. Both aging and $\mathrm{AD}$ feature commonalities in mitochondrial biology, and mitochondrial biology interacts with most of the accepted AD pathologies and pathways [8, 98]. Pursuing mitochondrial links between aging and $\mathrm{AD}$ may, therefore, lead to a better understanding of AD, which could lead to better interventions.

\section{Abbreviations}

Aß: Beta amyloid; AACD: Age-associated cognitive decline; AAMl: Age-associated memory impairment; AD: Alzheimer's disease; APP: Amyloid precursor protein; COX: Cytochrome oxidase; CSF: Cerebrospinal fluid; Cybrid: Cytoplasmic hybrid; FAD: Flavin adenine dinucleotide; HIF1a: Hypoxia induction factor 1 alpha; LOAD: Late-onset Alzheimer's disease; MCI: Mild cognitive impairment; mtDNA: Mitochondrial DNA; nDNA: Nuclear DNA; NAD: Nicotinamide adenine dinucleotide; ROS: Reactive oxygen species; SCD: Subjective cognitive decline.

\section{Acknowledgements}

The authors are supported by P30AG035982.

\section{Authors' contributions}

HMW and RHS wrote the paper. Both authors read and approved the final manuscript.

\section{Funding}

The authors are supported by P30AG035982. HMW is additionally supported by R00AG056600. 
Availability of data and materials

Not applicable.

\section{Declarations}

Ethics approval and consent to participate

Not applicable.

\section{Consent for publication}

Not applicable.

\section{Competing interests}

The authors declare no competing interests.

\section{Author details}

${ }^{1}$ University of Kansas Alzheimer's Disease Research Center, Kansas City, KS, USA. ${ }^{2}$ Departments of Neurology, University of Kansas Medical Center, Kansas City, KS, USA. ${ }^{3}$ Departments of Biochemistry and Molecular Biology, Medical Center, University of Kansas Medical Center, Kansas City, USA. ${ }^{4}$ Departments of Molecular and Integrative Physiology, Medical Center, University of Kansas Medical Center, Kansas City, KS, USA.

Received: 23 June 2021 Accepted: 21 August 2021

Published online: 01 September 2021

\section{References}

1. Lopez-Otin C, Blasco MA, Partridge L, Serrano M, Kroemer G. The hallmarks of aging. Cell. 2013;153(6):1194-217

2. Richards M, Touchon J, Ledesert B, Richie K. Cognitive decline in ageing: are AAMI and AACD distinct entities? Int J Geriatr Psychiatry. 1999:14(7):534-40.

3. Petersen RC. Clinical practice. Mild cognitive impairment. N Engl J Med. 2011;364(23):2227-2234.

4. Albert MS, DeKosky ST, Dickson D, Dubois B, Feldman HH, Fox NC, et al. The diagnosis of mild cognitive impairment due to Alzheimer's disease: recommendations from the National Institute on Aging-Alzheimer's Association workgroups on diagnostic guidelines for Alzheimer's disease. Alzheimers Dement. 2011;7(3):270-9.

5. Jessen F, Amariglio RE, Buckley RF, van der Flier WM, Han Y, Molinuevo $\mathrm{J}$, et al. The characterisation of subjective cognitive decline. Lancet Neurol. 2020;19(3):271-8.

6. Winblad B, Palmer K, Kivipelto M, Jelic V, Fratiglioni L, Wahlund LO, et al. Mild cognitive impairment-beyond controversies, towards a consensus: report of the International Working Group on Mild Cognitive Impairment. J Intern Med. 2004;256(3):240-6.

7. Jack CR Jr, Bennett DA, Blennow K, Carrillo MC, Dunn B, Haeberlein $\mathrm{SB}$, et al. NIA-AA research framework: toward a biological definition of Alzheimer's disease. Alzheimers Dement. 2018;14(4):535-62.

8. Swerdlow RH, Koppel S, Weidling I, Hayley C, Ji Y, Wilkins HM. Mitochondria, cybrids, aging, and Alzheimer's disease. Prog Mol Biol Transl Sci. 2017;146:259-302

9. Scarpulla RC. Transcriptional paradigms in mammalian mitochondrial biogenesis and function. Physiol Rev. 2008;88(2):611-38.

10. Youle RJ, Narendra DP. Mechanisms of mitophagy. Nat Rev Mol Cell Biol. 2011:12(1):9-14

11. Chan DC. Mitochondrial fusion and fission in mammals. Annu Rev Cell Dev Biol. 2006;22:79-99.

12. Chen $\mathrm{H}$, Chan DC. Mitochondrial dynamics-fusion, fission, movement, and mitophagy-in neurodegenerative diseases. Hum Mol Genet. 2009;18(R2):R169-176.

13. Liu Z, Butow RA. Mitochondrial retrograde signaling. Annu Rev Genet. 2006:40:159-85.

14. Johnson DT, Harris RA, French S, Blair PV, You J, Bemis KG, et al. Tissue heterogeneity of the mammalian mitochondrial proteome. Am J Physiol Cell Physiol. 2007;292(2):C689-697.

15. Arendt T, Stieler J, Strijkstra AM, Hut RA, Rudiger J, Van der Zee EA, et al. Reversible paired helical filament-like phosphorylation of tau is an adaptive process associated with neuronal plasticity in hibernating animals. J Neurosci. 2003;23(18):6972-81.

16. Jernberg JN, Bowman CE, Wolfgang MJ, Scafidi S. Developmental regulation and localization of carnitine palmitoyltransferases (CPTs) in rat brain. J Neurochem. 2017;142(3):407-19.

17. Guzman M, Blazquez C. Is there an astrocyte-neuron ketone body shuttle? Trends Endocrinol Metab. 2001;12(4):169-73.

18. Pellerin L, Magistretti PJ. Neuroenergetics: calling upon astrocytes to satisfy hungry neurons. Neuroscientist. 2004;10(1):53-62.

19. Theurey P, Pizzo P. The Aging Mitochondria. Genes. 2018;9(1).

20. Linnane AW, Marzuki S, Ozawa T, Tanaka M. Mitochondrial DNA mutations as an important contributor to ageing and degenerative diseases. Lancet. 1989; 1(8639):642-5.

21. Corral-Debrinski M, Horton T, Lott MT, Shoffner JM, Beal MF, Wallace DC Mitochondrial DNA deletions in human brain: regional variability and increase with advanced age. Nat Genet. 1992;2(4):324-9.

22. Filograna R, Mennuni M, Alsina D, Larsson NG. Mitochondrial DNA copy number in human disease: the more the better? FEBS Lett. 2021;595(8):976-1002.

23. Guo W, Jiang L, Bhasin S, Khan SM, Swerdlow RH. DNA extraction procedures meaningfully influence qPCR-based mtDNA copy number determination. Mitochondrion. 2009:9(4):261-5.

24. Beal MF. Oxidatively modified proteins in aging and disease. Free Radic Biol Med. 2002;32(9):797-803.

25. Mecocci P, MacGarvey U, Kaufman AE, Koontz D, Shoffner JM, Wallace $D C$, et al. Oxidative damage to mitochondrial DNA shows marked agedependent increases in human brain. Ann Neurol. 1993:34(4):609-16.

26. Harman D. Aging: a theory based on free radical and radiation chemistry. J Gerontol. 1956;11(3):298-300.

27. Harman D. The biologic clock: the mitochondria? J Am Geriatr Soc. 1972:20(4):145-7.

28. Smigrodzki RM, Khan SM. Mitochondrial microheteroplasmy and a theory of aging and age-related disease. Rejuvenation Res. 2005;8(3):172-98.

29. Wallace DC. Mitochondrial genetics: a paradigm for aging and degenerative diseases? Science. 1992;256(5057):628-32.

30. Kujoth GC, Hiona A, Pugh TD, Someya S, Panzer K, Wohlgemuth SE, et al. Mitochondrial DNA mutations, oxidative stress, and apoptosis in mammalian aging. Science. 2005;309(5733):481-4.

31. Trifunovic A, Wredenberg A, Falkenberg M, Spelbrink JN, Rovio AT, Bruder CE, et al. Premature ageing in mice expressing defective mitochondrial DNA polymerase. Nature. 2004:429(6990):417-23.

32. Kraytsberg Y, Simon DK, Turnbull DM, Khrapko K. Do mtDNA deletions drive premature aging in mtDNA mutator mice? Aging Cell. 2009;8(4):502-6.

33. Vermulst M, Bielas JH, Kujoth GC, Ladiges WC, Rabinovitch PS, Prolla TA, et al. Mitochondrial point mutations do not limit the natural lifespan of mice. Nat Genet. 2007;39(4):540-3

34. Bratic A, Larsson NG. The role of mitochondria in aging. J Clin Invest. 2013;123(3):951-7.

35. Hiona A, Sanz A, Kujoth GC, Pamplona R, Seo AY, Hofer T, et al. Mitochondrial DNA mutations induce mitochondrial dysfunction, apoptosis and sarcopenia in skeletal muscle of mitochondrial DNA mutator mice. PLoS One. 2010;5(7):e11468.

36. Jang YC, Remmen $\mathrm{VH}$. The mitochondrial theory of aging: insight from transgenic and knockout mouse models. Exp Gerontol. 2009:44(4):256-60.

37. Schriner SE, Linford NJ, Martin GM, Treuting P, Ogburn CE, Emond $\mathrm{M}$, et al. Extension of murine life span by overexpression of catalase targeted to mitochondria. Science. 2005;308(5730):1909-11.

38. Munkacsy E, Rea SL. The paradox of mitochondrial dysfunction and extended longevity. Exp Gerontol. 2014;56:221-33.

39. Finkel T. Reactive oxygen species and signal transduction. IUBMB Life. 2001:52(1-2):3-6.

40. Chandel NS, Maltepe E, Goldwasser E, Mathieu CE, Simon MC, Schumacker PT. Mitochondrial reactive oxygen species trigger hypoxiainduced transcription. Proc Natl Acad Sci U S A. 1998;95(20):11715-20.

41. Lee $S$, Hwang AB, Kenyon C. Inhibition of respiration extends $C$. elegans life span via reactive oxygen species that increase HIF-1 activity. Curr Biol. 2010;20(23):2131-2136. 
42. Swerdlow RH. Mitochondria and cell bioenergetics: increasingly recognized components and a possible etiologic cause of Alzheimer's disease. Antioxid Redox Signal. 2012;16(12):1434-55.

43. Wang W, Zhao F, Ma X, Perry G, Zhu X. Mitochondria dysfunction in the pathogenesis of Alzheimer's disease: recent advances. Mol Neurodegener. 2020;15(1):30.

44. Oliver DMA, Reddy PH. Molecular basis of Alzheimer's disease: focus on mitochondria. J Alzheimers Dis. 2019;72(s1):S95-s116.

45. Cardoso S, Carvalho C, Correia SC, Seiça RM, Moreira PI. Alzheimer's disease: from mitochondrial perturbations to mitochondrial medicine. Brain Pathol. 2016;26(5):632-47.

46. Parker WD Jr, Filley CM, Parks JK. Cytochrome oxidase deficiency in Alzheimer's disease. Neurology. 1990;40(8):1302-3.

47. Kish SJ, Bergeron C, Rajput A, Dozic S, Mastrogiacomo F, Chang LJ, et al. Brain cytochrome oxidase in Alzheimer's disease. J Neurochem. 1992;59(2):776-9.

48. Curti D, Rognoni F, Gasparini L, Cattaneo A, Paolillo M, Racchi M, et al. Oxidative metabolism in cultured fibroblasts derived from sporadic Alzheimer's disease (AD) patients. Neurosci Lett. 1997;236(1):13-6.

49. Valla J, Schneider L, Niedzielko T, Coon KD, Caselli R, Sabbagh MN, et al. Impaired platelet mitochondrial activity in Alzheimer's disease and mild cognitive impairment. Mitochondrion. 2006;6(6):323-30.

50. Swerdlow RH. Mitochondria and mitochondrial cascades in Alzheimer's disease. J Alzheimers Dis. 2018:62(3):1403-16.

51. Mecocci P, MacGarvey U, Beal MF. Oxidative damage to mitochondrial DNA is increased in Alzheimer's disease. Ann Neurol. 1994;36(5):747-51.

52. Manczak M, Calkins MJ, Reddy PH. Impaired mitochondrial dynamics and abnormal interaction of amyloid beta with mitochondrial protein Drp1 in neurons from patients with Alzheimer's disease: implications for neuronal damage. Hum Mol Genet. 2011;20(13):2495-509.

53. Wang X, Su B, Lee HG, Li X, Perry G, Smith MA, et al. Impaired balance of mitochondrial fission and fusion in Alzheimer's disease. J Neurosci. 2009;29(28):9090-103.

54. Wang X, Su B, Siedlak SL, Moreira PI, Fujioka H, Wang Y, et al. Amyloidbeta overproduction causes abnormal mitochondrial dynamics via differential modulation of mitochondrial fission/fusion proteins. Proc Natl Acad Sci U S A. 2008;105(49):19318-23.

55. Wang X, Su B, Fujioka H, Zhu X. Dynamin-like protein 1 reduction underlies mitochondrial morphology and distribution abnormalities in fibroblasts from sporadic Alzheimer's disease patients. Am J Pathol. 2008;173(2):470-82.

56. Baloyannis SJ. Mitochondrial alterations in Alzheimer's disease. J Alzheimers Dis. 2006;9(2):119-26.

57. Baloyannis SJ, Costa V, Michmizos D. Mitochondrial alterations in Alzheimer's disease. Am J Alzheimers Dis Other Demen. 2004;19(2):89-93.

58. Qin W, Haroutunian V, Katsel P, Cardozo CP, Ho L, Buxbaum JD, et al. PGC-1alpha expression decreases in the Alzheimer disease brain as a function of dementia. Arch Neurol. 2009;66(3):352-61.

59. Sheng B, Wang X, Su B, Lee HG, Casadesus G, Perry G, et al. Impaired mitochondrial biogenesis contributes to mitochondrial dysfunction in Alzheimer's disease. J Neurochem. 2012;120(3):419-29.

60. Kerr JS, Adriaanse BA, Greig NH, Mattson MP, Cader MZ, Bohr VA, et al. Mitophagy and Alzheimer's disease: cellular and molecular mechanisms. Trends Neurosci. 2017;40(3):151-66.

61. Hirai K, Aliev G, Nunomura A, Fujioka H, Russell RL, Atwood CS, et al. Mitochondrial abnormalities in Alzheimer's disease. J Neurosci. 2001;21(9):3017-23.

62. Perry G, Nunomura A, Hirai K, Zhu X, Perez M, Avila J, et al. Is oxidative damage the fundamental pathogenic mechanism of Alzheimer's and other neurodegenerative diseases? Free Radic Biol Med. 2002;33(11):1475-9.

63. Ogunshola O, Antoniou X. Contribution of hypoxia to Alzheimer's disease: Is HIF-1a a mediator of neurodegeneration? CMLS. 2009;66:3555-63.

64. Thomas LW, Ashcroft M. Exploring the molecular interface between hypoxia-inducible factor signalling and mitochondria. Cell Mol Life Sci. 2019;76(9):1759-77

65. Semenza GL. Hypoxia-inducible factors in physiology and medicine. Cell. 2012;148(3):399-408.

66. de la Monte SM, Luong T, Neely TR, Robinson D, Wands JR. Mitochondrial DNA damage as a mechanism of cell loss in Alzheimer's disease.
Laboratory investigation; a journal of technical methods and pathology 2000;80(8):1323-1335.

67. Brown AM, Sheu RK, Mohs R, Haroutunian V, Blass JP. Correlation of the clinical severity of Alzheimer's disease with an aberration in mitochondrial DNA (mtDNA). J Mol Neurosci. 2001;16(1):41-8.

68. Wei W, Keogh MJ, Wilson I, Coxhead J, Ryan S, Rollinson S, et al. Mitochondrial DNA point mutations and relative copy number in 1363 disease and control human brains. Acta Neuropathol Commun. 2017;5(1):13

69. Krishnan KJ, Ratnaike TE, De Gruyter HL, Jaros E, Turnbull DM. Mitochondrial DNA deletions cause the biochemical defect observed in Alzheimer's disease. Neurobiol Aging. 2012;33(9):2210-4.

70. Podlesniy P, Figueiro-Silva J, Llado A, Antonell A, Sanchez-Valle R, Alcolea D, et al. Low cerebrospinal fluid concentration of mitochondrial DNA in preclinical Alzheimer disease. Ann Neurol. 2013.

71. Davis RE, Miller S, Herrnstadt C, Ghosh SS, Fahy E, Shinobu LA, et al. Mutations in mitochondrial cytochrome c oxidase genes segregate with late-onset Alzheimer disease. Proc Natl Acad Sci U S A. 1997;94(9):4526-31.

72. Swerdlow RH. Mitochondria in cybrids containing mtDNA from persons with mitochondriopathies. J Neurosci Res. 2007;85(15):3416-28.

73. Swerdlow RH, Parks JK, Cassarino DS, Maguire DJ, Maguire RS, Bennett JP Jr, et al. Cybrids in Alzheimer's disease: a cellular model of the disease? Neurology. 1997;49(4):918-25.

74. Gomez-Duran A, Pacheu-Grau D, Lopez-Gallardo E, Diez-Sanchez C, Montoya J, Lopez-Perez MJ, et al. Unmasking the causes of multifactorial disorders: OXPHOS differences between mitochondrial haplogroups. Hum Mol Genet. 2010;19(17):3343-53.

75. Swerdlow RH, Hui D, Chalise P, Sharma P, Wang X, Andrews SJ, et al. Exploratory analysis of mtDNA haplogroups in two Alzheimer's longitudinal cohorts. Alzheimers Dement. 2020;16(8):1164-72.

76. Coskun PE, Beal MF, Wallace DC. Alzheimer's brains harbor somatic mtDNA control-region mutations that suppress mitochondrial transcription and replication. Proc Natl Acad Sci U S A. 2004;101(29):10726-31.

77. Weidling IW, Wilkins HM, Koppel SJ, Hutfles L, Wang X, Kalani A, et al. Mitochondrial DNA manipulations affect tau oligomerization. J Alzheimers Dis. 2020;77(1):149-63.

78. Anandatheerthavarada HK, Biswas G, Robin MA, Avadhani NG. Mitochondrial targeting and a novel transmembrane arrest of Alzheimer's amyloid precursor protein impairs mitochondrial function in neuronal cells. J Cell Biol. 2003;161(1):41-54.

79. Anandatheerthavarada HK, Devi L. Amyloid precursor protein and mitochondrial dysfunction in Alzheimer's disease. Neuroscientist. 2007;13(6):626-38.

80. Devi L, Prabhu BM, Galati DF, Avadhani NG, Anandatheerthavarada HK. Accumulation of amyloid precursor protein in the mitochondrial import channels of human Alzheimer's disease brain is associated with mitochondrial dysfunction. J Neurosci. 2006;26(35):9057-68.

81. Lustbader JW, Cirilli M, Lin C, Xu HW, Takuma K, Wang N, et al. ABAD directly links Abeta to mitochondrial toxicity in Alzheimer's disease. Science. 2004;304(5669):448-52.

82. Manczak M, Anekonda TS, Henson E, Park BS, Quinn J, Reddy PH. Mitochondria are a direct site of A beta accumulation in Alzheimer's disease neurons: implications for free radical generation and oxidative damage in disease progression. Hum Mol Genet. 2006;15(9):1437-49.

83. Du H, Guo L, Fang F, Chen D, Sosunov AA, McKhann GM, et al. Cyclophilin $D$ deficiency attenuates mitochondrial and neuronal perturbation and ameliorates learning and memory in Alzheimer's disease. Nat Med. 2008;14(10):1097-105.

84. Crouch PJ, Blake R, Duce JA, Ciccotosto GD, Li QX, Barnham KJ, et al. Copper-dependent inhibition of human cytochrome c oxidase by a dimeric conformer of amyloid-beta 1-42. J Neurosci. 2005;25(3):672-9.

85. Hansson Petersen CA, Alikhani N, Behbahani H, Wiehager B, Pavlov PF, Alafuzoff I, et al. The amyloid beta-peptide is imported into mitochondria via the TOM import machinery and localized to mitochondrial cristae. Proc Natl Acad Sci U S A. 2008;105(35):13145-50.

86. Kopeikina KJ, Carlson GA, Pitstick R, Ludvigson AE, Peters A, Luebke Jl, et al. Tau accumulation causes mitochondrial distribution deficits in 
neurons in a mouse model of tauopathy and in human Alzheimer's disease brain. Am J Pathol. 2011;179(4):2071-82.

87. Jara C, Aránguiz A, Cerpa W, Tapia-Rojas C, Quintanilla RA. Genetic ablation of tau improves mitochondrial function and cognitive abilities in the hippocampus. Redox Biol. 2018;18:279-94.

88. Rhein V, Song X, Wiesner A, Ittner LM, Baysang G, Meier F, et al. Amyloidbeta and tau synergistically impair the oxidative phosphorylation system in triple transgenic Alzheimer's disease mice. Proc Natl Acad Sci U S A. 2009;106(47):20057-62.

89. Hu Y, Li XC, Wang ZH, Luo Y, Zhang X, Liu XP, et al. Tau accumulation impairs mitophagy via increasing mitochondrial membrane potential and reducing mitochondrial Parkin. Oncotarget. 2016;7(14):17356-68.

90. Choi J, Chandrasekaran K, Demarest TG, Kristian T, Xu S, Vijaykumar K, et al. Brain diabetic neurodegeneration segregates with low intrinsic aerobic capacity. Annals Clin Transl Neurol. 2014;1 (8):589-604.

91. Cheng Y, Bai F. The Association of Tau with mitochondrial dysfunction in Alzheimer's disease. Front Neurosci. 2018;12:163.

92. Szabo L, Eckert A, Grimm A. Insights into disease-associated Tau impact on mitochondria. Int J Mol Sci. 2020;21(17).

93. Chang S, ran Ma T, Miranda RD, Balestra ME, Mahley RW, Huang Y. Lipidand receptor-binding regions of apolipoprotein E4 fragments act in concert to cause mitochondrial dysfunction and neurotoxicity. Proc Natl Acad Sci U S A. 2005;102(51):18694-18699.

94. Chen HK, Ji ZS, Dodson SE, Miranda RD, Rosenblum Cl, Reynolds IJ, et al. Apolipoprotein E4 domain interaction mediates detrimental effects on mitochondria and is a potential therapeutic target for Alzheimer disease. J Biol Chem. 2011;286(7):5215-21.

95. Wilkins HM, Koppel SJ, Bothwell R, Mahnken J, Burns JM, Swerdlow RH. Platelet cytochrome oxidase and citrate synthase activities in APOE epsilon4 carrier and non-carrier Alzheimer's disease patients. Redox Biol. 2017;12:828-32.

96. Wilkins HM, Wang X, Menta BW, Koppel SJ, Bothwell R, Becker AM, et al. Bioenergetic and inflammatory systemic phenotypes in Alzheimer's disease APOE \&4-carriers. Aging cell. 2021;20(5):e13356.

97. Menta BW, Swerdlow RH. An integrative overview of non-amyloid and non-tau pathologies in Alzheimer's disease. Neurochem Res. 2019;44(1):12-21.

98. Swerdlow RH, Burns JM, Khan SM. The Alzheimer's disease mitochondrial cascade hypothesis: progress and perspectives. Biochim Biophys Acta. 2014;1842(8):1219-31.

99. Swerdlow RH, Burns JM, Khan SM. The Alzheimer's disease mitochondrial cascade hypothesis. J Alzheimers Dis. 2010:20(Suppl 2):S265-279.

100. Swerdlow RH, Khan SM. A "mitochondrial cascade hypothesis" for sporadic Alzheimer's disease. Med Hypotheses. 2004;63(1):8-20.

101. Swerdlow RH. The mitochondrial hypothesis: Dysfunction, bioenergetic defects, and the metabolic link to Alzheimer's disease. Int Rev Neurobiol. 2020;154:207-33.

102. Alzheimer A. Uber eine eigenartige Erkrankung der Hirnrinde. Allg Z Psychiat Psych-Gerichtl Med. 1907;64:146-8.

103. Alzheimer A, Stelzmann RA, Schnitzlein HN, Murtagh FR. An English translation of Alzheimer's 1907 paper, "Uber eine eigenartige Erkankung der Hirnrinde." Clin Anat. 1995;8(6):429-31.

104. Karch CM, Goate AM. Alzheimer's disease risk genes and mechanisms of disease pathogenesis. Biol Psychiatry. 2015;77(1):43-51.

105. Johnson ECB, Dammer EB, Duong DM, Ping L, Zhou M, Yin L, et al. Large-scale proteomic analysis of Alzheimer's disease brain and cerebrospinal fluid reveals early changes in energy metabolism associated with microglia and astrocyte activation. Nat Med. 2020;26(5):769-80

106. Swerdlow RH. Is aging part of Alzheimer's disease, or is Alzheimer's disease part of aging? Neurobiol Aging. 2007;28(10):1465-80.

107. Gabuzda D, Busciglio J, Chen LB, Matsudaira P, Yankner BA. Inhibition of energy metabolism alters the processing of amyloid precursor protein and induces a potentially amyloidogenic derivative. J Biol Chem. 1994:269(18):13623-8.

108. Gasparini L, Racchi M, Benussi L, Curti D, Binetti G, Bianchetti A, et al. Effect of energy shortage and oxidative stress on amyloid precursor protein metabolism in COS cells. Neurosci Lett. 1997;231(2):113-7.
109. Webster MT, Pearce BR, Bowen DM, Francis PT. The effects of perturbed energy metabolism on the processing of amyloid precursor protein in PC12 cells. J Neural Transm. 1998;105(8-9):839-53.

110. Lei P, Ayton S, Bush Al. The essential elements of Alzheimer's disease. J Biol Chem. 2020;296.

111. Blass JP, Baker AC, Ko L, Black RS. Induction of Alzheimer antigens by an uncoupler of oxidative phosphorylation. Arch Neurol. 1990;47(8):864-9.

112. Szabados T, Dul C, Majtenyi K, Hargitai J, Penzes Z, Urbanics R. A chronic Alzheimer's model evoked by mitochondrial poison sodium azide for pharmacological investigations. Behav Brain Res. 2004;154(1):31-40.

113. Escobar-Khondiker M, Hollerhage M, Muriel MP, Champy P, Bach A, Depienne C, et al. Annonacin, a natural mitochondrial complex I inhibitor, causes tau pathology in cultured neurons. J Neurosci. 2007;27(29):7827-37.

114. Rottscholl R, Haegele M, Jainsch B, Xu H, Respondek G, Hollerhage $M$, et al. Chronic consumption of Annona muricata juice triggers and aggravates cerebral tau phosphorylation in wild-type and MAPT transgenic mice. J Neurochem. 2016;139(4):624-39.

115. Hoglinger GU, Lannuzel A, Khondiker ME, Michel PP, Duyckaerts C, Feger J, et al. The mitochondrial complex I inhibitor rotenone triggers a cerebral tauopathy. J Neurochem. 2005;95(4):930-9.

116. Yamada ES, Respondek G, Mussner S, de Andrade A, Hollerhage M, Depienne C, et al. Annonacin, a natural lipophilic mitochondrial complex I inhibitor, increases phosphorylation of tau in the brain of FTDP-17 transgenic mice. Exp Neurol. 2014;253:113-25.

117. Hollerhage M, Deck R, De Andrade A, Respondek G, Xu H, Rosler TW, et al. Piericidin A aggravates Tau pathology in P301S transgenic mice. PLoS One. 2014;9(12):e113557.

118. Yamazaki Y, Zhao N, Caulfield TR, Liu CC, Bu G. Apolipoprotein E and Alz heimer disease: pathobiology and targeting strategies. Nat Rev Neurol. 2019;15(9):501-18.

119. Mahley RW, Huang Y. Apolipoprotein e sets the stage: response to injury triggers neuropathology. Neuron. 2012;76(5):871-85.

120. Mahley RW, Weisgraber KH, Huang Y. Apolipoprotein E4: a causative factor and therapeutic target in neuropathology, including Alzheimer's disease. Proc Natl Acad Sci U S A. 2006;103(15):5644-51.

121. Zalocusky KA, Najm R, Taubes AL, Hao Y, Yoon SY, Koutsodendris N, et al. Neuronal ApoE upregulates MHC-I expression to drive selective neurodegeneration in Alzheimer's disease. Nat Neurosci. 2021;24(6):786-98.

122. Hardy J, Allsop D. Amyloid deposition as the central event in the aetiology of Alzheimer's disease. Trends Pharmacol Sci. 1991;12(10):383-8.

123. Aizenstein HJ, Nebes RD, Saxton JA, Price JC, Mathis CA, Tsopelas ND, et al. Frequent amyloid deposition without significant cognitive impairment among the elderly. Arch Neurol. 2008;65(11):1509-17.

124. Rowe CC, Ng S, Ackermann U, Gong SJ, Pike K, Savage G, et al. Imaging beta-amyloid burden in aging and dementia. Neurology. 2007;68(20):1718-25

125. Khosravi M, Peter J, Wintering NA, Serruya M, Shamchi SP, Werner $\mathrm{T}$, et al. ${ }^{18} \mathrm{~F}-\mathrm{FDG}$ is a superior indicator of cognitive performance compared to ${ }^{18} \mathrm{~F}$-Florbetapir in Alzheimer's disease and mild cognitive impairment evaluation: a global quantitative analysis. J Alzheimers Dis. 2019;70(4):1197-207.

126. Panza F, Lozupone $M$, Logroscino G, Imbimbo BP. A critical appraisal of amyloid- $\beta$-targeting therapies for Alzheimer disease. Nat Rev Neurol. 2019:15(2):73-88.

127. Tapia-Rojas C, Cabezas-Opazo F, Deaton CA, Vergara EH, Johnson GVW, Quintanilla RA. It's all about tau. Prog Neurobiol. 2019;175:54-76.

128. Murray ME, Lowe VJ, Graff-Radford NR, Liesinger AM, Cannon A, Przybelski SA, et al. Clinicopathologic and 11C-Pittsburgh compound B implications of Thal amyloid phase across the Alzheimer's disease spectrum. Brain. 2015;138(Pt 5):1370-81. 